\section{A Saries of OHrininal Artirlez}

\section{THE PLAGUE.}

\section{THE SIGNS AND SYMPTOMS OF BUBONIC, PNEUMONIC, AND SEPTIC AMIC PLAGUE,}

By JAMES CANTLIE, M.B., F.R.C.S., Lecturer, London School of Tropical Medicine.

UNTIL quite recently plague was termed "bubonic" in the belief that buboes were an essential factor in the characterisation of the disease. It is, however, now known that the disease may run its course without either buboes or even enlarged glands appearing; and that in non-bubonic cases other signs and symptoms present themselves to which a nomenclature in accordance with the most salient feature of the illness has been applied.

There are three main types of plague, the BoBonic, the Pnedmonic, and the Septic femic ; and under some one of these all cases of plague can be grouped. Such terms as fulminant, toxic, siderans, puerperal, intestinal, gastric, typhoid type, convulsive or nervous type, typhus type, applied to plague cases, refer either to the severicy of the illness or to the more prominent symptoms which obtain.

\section{I.-Bubonio Plague.}

In every epidemic, since plague appeared in 1894 in Hong Kong and became pandemic, the bubonic variety of plague has never formed less than 70 per cent. of the cases met with. In many outbreaks almost every case develops buboes, but in others one in every three cases is non-bubonic in character.

The history of a case of plague is best considered under the headings of exposure, incubation, invasion, eruption of buboes, defervescence, and convalescence.

Exposure and Spread.-The most potent agent in the spread of plague is undoubtedly contact with persons suffering from the disease. Plague spreads from one member of a household to another, and from one $h$ unse to another, in a neighbourhood in which it prevails, with a tenacity and persistency which indicates a "house infection." In an uncontaminated district, however, individual cases occur which may prove purely sporadic, and infection seems to depend rather upon a prolonged and intimate contact. Environment also would seem to play a prominent part; for in hospitals, doctors, nurses, and attendants escape infection in so marked a manner that the plague hospital has in many cities come to be looked upon as the locality in which infection is least likely to occur. This is, however, true of almost all infectious disorders, for in our fever hospitals, whatever the nature of the illness, the same feature would appear to hold good ; cleanliness, ventilation, and observance of ordinary sanitary principles being seemingly efficacious in preventing infection. The skin is at the present time considered by the majority of observers to be the channel by which the plague bacillus finds entrance. The unbroken skin is believed to be uninoculable by plague, but wounds, cracks, fissures, the bites of insects, the scratching which body parasites induce, or any solution of continuity of the skin are considered as possible paths by which the plague virus may enter. In support of this contention there are several clinical and experimental proofs which seem to justify the belief that abrasions or wounds of the skin are transmission channels for the plague bacillus. In the first place, the groin glands are the usual seat of buboes in plague, and, as the majority of plague patients in Asiatic communities go barefooted, the circumstances would seem to stand to each other as cause and effect. Again, when a loral wound or injury is found in the extremities of persons suffering from plague, it is usually the gland nearest the seat of possible infection that is primarily inflamed. When the cervical glands are the seat of buboes, the virus is presumed to enter by way of the tonsil, and, in confirmation of the local infective methods of entrance, it is in such cases that the tonsils are found to be inflamed. Against the argument of infection by way of the skin is the fact that, although the hands of Europeans engaged on " plague duty " are more exposed than the lower limbs, still it is the lower, much more frequently than the upper, limb glands which become inflamed. Experiments on animals also throw doubt on the likelihood of a bubo being an expression of local inoculation.

Infection by way of the alimentary canal would seem feasible and probable judging by the swarms of plague bacilli met with in the fæces, and from the fact that animals such as rats and mice fed on the viscera of animals dead of plague readily contract plague. Still there is no direct proof that either food or water serve to convey plague to human beings. Infection by the breath is unlikely, although the bacilli in the sputam of pneumonic cases exist in almost a pure culture. The breath can only contaminate by the medium of the air, but the bacillus pestis has never been isolated from the air. The impact if the sputum of patients suffering from pneumonic plague on the conjanctiva is, however, believed to have caused infection in more than one instance.

The rat, in common with some other auimals, is subject to plague, and in most epidemics the plague bacillus has been lound in the bodies of the rats, and the mortality amongst them has been high. As yet it is unascertained whether the rat is attacked prior to, concomitantly with, or subsequent to the appearance of the disease in man; but in certain limited outbreaks, such as that recently experienced in Glasgow, the rat has not been proved to be infected at all.

Not a few observers claim that it is the vermin inhabiting the coat of the rat that convey the infection to man. These have been shown to harbour the plague bacillus, and to leave the rat's body soon after the animal dies. And it is maintained that persons handling recently dead rats are liable to be inoculated by the vermin. Against this contention, however, it is asserted that the vermin of the rat's coat do not bite man. The body parasites of man such as lice, fleas, and bugs, in common with flies, ants, etc., also absorb the plague bacillus, and it is possible that by the bites of parasites, or by the excoriations caused by the scratching they induce, the plague bacillus may find entrance into man.

It will be seen from the above statements that the exact method by which human beings become exposed to plague is not definitely known.

Incubation-The average period of incubation is from three to five days ; and, although it is believed that the disease may have a shorter period of incubation, lasting only thirty-six hours, or for a longer period, extending to ten or even fourteen days, the maximum and minimum periods of incubation are undetermined. No specific train of symptoms is peculiar to the period of incubation. General malaise and some discomfort are occasionally experienced during the incubation of plague, but they are not characteristic, and are often altogether absent.

Invasion.-The onset of plague is generally sudden. The patient complains of a splitting headache, of great weakness and prostration, of pains in the limbs and back, and it may be of prin in some one of the larger groups of lymphatic glands. Rigors or a feeling of chill almost invariably herald the period of invasion in severe cases, and vomiting and nausea may usher in the disease and may continue for a day or two. Diarrhœe is not uncommon as an initial symptom. The pulse is usually fairly full at first, and increased in frequency; the breathing rate is augmented, and the temperature may gradually rise during the first three days, until a temperature of $104^{\circ}, 105^{\circ} \mathrm{F}$., or higher is reached, or the thermometer may register $105^{\circ}$ soon after the onset. Mental aberration appears early, and the patient may wear a fatuous, listless, or unconcerned expression; or a pain-drawn, haggard expression may obtain from the commencement of the illness. Delirium or convulsions in children occasionally usher in the disease. Beyond the marked prostration and the early appearance of cerebral disturbance, however, there is nothing indicative of a specific ailment until the tenderness in the glands, or a bubo, appears. It is, as a rule, the third day before the bubo appears, but when it does and when it is taken in conjunction with the constitutional symptoms, the nature of the disease, as far as clinical evidence can determine, is established.

The Cutaneous System-Abrasions of the skin should be sought for; more especially in the lower extremities, when the groin glands are enlarged. The hands, wrists, and forearms 
should be similarly examined when the axillary glands are swollen; and the lips for cracks, or the tonsils for inflammatory evidence, when the cervical glands are enlarged and tender. Boils and so-called carbuncles are rarely met with. A rash is uncommon, but when it is present it will usually be seen on or around the bubo, and only a day or two before death. Petechim are sometimes in evidence in diverse parts of the limbs or trunk, and discoloration due to extensive subcutaneous hæmorrhage for a considerable distance around a bubo is a fairly frequent occurrence. A few cases in every extensive epidemic of plague exhibit a rash almost identical with that in malignant typhus.

Iymphatic System.-Adenitis occurs in all varieties of plague except in the pneumonic and fulminant, and the absence of glandular swelling in them may be accounted for by the prostration which prevents a reaction and by the rapidly fatal issue. In bubonic plague unilateral swelling of a group of glands is the rule (See Special Plate, Fig. 2), and one gland of the group proceeds to bubo. Bilateral enlargement is, however, not infrequently met with, or the glands in one axilla and the glands of the opposite groin may develop synchronously. Tenderness to pressure in the region of the affected group of glands usually precedes apparent enlargement; and pain, at times of an excruciating character, with hyperæsthesia, appears early. It is usually during the third day of the illness that the bubo develops; but it may accompany or even anticipate constitutional symptoms, or it may delay its appearance for five or six or more days. A lymphatic gland in the femoral region, when fairly well advanced, may attain the shape and size of of a pigeon's egg, but the periglandular effusion which almost invariably accompanies it renders the outline obscure, when it resembles a bath bun in dimensions and outline. The skin, at first of a normal colour soon becomes congested, the colour deepening to a purplish tinge, or petechiæ may appear upon it. The tumour feels elastic and resilient, and the surrounding tissues early become œdematous, the œdema extending over the lower part of the abdomen, Scarpa's triangle, and the gluteal region. Subcutaneous hæmorrhage in this region is of frequent occurrence, the effused blood extending many inches in all directions, or it may follow one direction only, reaching well down the thigh or backwards over the gluteal region.

The pain and swelling set up by the bubo cause the patient to take up a position by which the fascia in its neighbourhood is relaxed; thus, when the groin is the seat of the swelling the thigh is flexed, or the patient may prefer to sit up on the bed to procure the maximum of flexion of the limb. When the axillary glands are swollen the arm is placed well away from the side, and the body is inclined towards the affected side, the swelling in this region at times reaching across the chest, down to the ilium, and backwards over the scapula. When the cervical glands are enlarged those in the neighbourhood of the angle of the jaw are usually the first to be enlarged, and the subsequent periglandular cedema mas extend downwards, backwards, and upwards over the side of the neck (see Special Plate, Fig. 1), and may be 80 pronounced as to cause pressure on the larynx and trachea, and some dyspnce.

Suppuration takes place early in the gland and periglandular tissue, but it is usually not until the eighth or tenth day that the skin over it sloughs, when a large ulcerated surface is left. with undermined and rather ragged edges. The remains of the necrosed gland may be seen at the bottom of the wound, or all definite traces of it may have disappeared, or they may escape with the slough and initial exit of pus.

When the fluid from a gland or periglandular swelling is drawn off early in the attack by a hypodermic syringe, it will usually be found to be of a sero-sanguinolent character, but later it becomes sero-purulent, and finally pus. In this fluid the plague bacillus will be found to be present in numbers; but in the pus flowing from the ulcerated surface of $a$ bubo of some days' standing no trace of the bacillus may be found.

Alimentary Canal.-The lips early in the disease become dry and cracked, the teeth covered with sordes. The tongue is at first covered with a thick dorsal white fur; the whole organ appears swollen, and the edges marked by the teeth. Soon the white fur assumes a mahogany tinge, or becomes almost black on the centre and back of the tongue. Later in the illness the tongue appears contracted, cracked, and dry. The throat and tonsils look red and congested, or the tonsils may be actually inflamed. Nausea and vomiting frequently usher in the disease, and may continue for a day or two, or may persist to the end. The vomited matters are at first of a bilions character, but afterwards may be very profuse and watery, or the ingesta may be ejected almost unchanged. A coffee-ground looking material is occasionally vomited, but hæmatemesis is not a feature of the disease. Constipation is the rule during the first day or two of the illness, followed frequently by diarrhca. Diarrhcea on the other hand may usher in the disease, but it is seldom the intestinal flux is frequent or profuse. Blood is not uncommonly present in the fæcal evacuations. The liver may be tender, and somewhat enlarged; the spleen is invariable swollen, and even in quite an early stage of the disease may attain three or four or more times its normal proportions. The urine as a rule is slightly albuminous : scanty from the first, it usually continues to be so. Suppression of urine with lumbar pains is not uncommon; it may obtain from the onset, but is more frequently observed towards the end in fatal cases; the urine is frequently retained. Granular casts and blood corpuscles are met with microscopically, or the blood may be in large quantity. Urea, uric acid, and the chlorides are deficient.

The Circulatory System.-Frequency in the rate of the pulse prevails at the onset and throughout the illness. At first it is fairly full, but after a day or two it becomes soft, compressible, and dicrotic, and towards the end irregular and running. The apex beat of the heart is diffuse, and occasionally a precordial thrill is present. Dilatation of the right side, a weak second sound, a shortened first sound, with occasionally a systolic murmur sum up the cardiac abnormalities met with in plague.

The Respiratory System. - In bubonic plague the lungs seldom show any departure from the normal, and it is only in the last few hours of life in fatal cases that any bronchial râles are heard. The breathing is hastened in all cases, and should the cervical glands be the seat of swelling and œdema, dyspnca may be present owing to pressure on the respiratory tract in the neck. In pneumonic plague the lungs are early attacked.

The Nervous System.-The cerebral functions betray early aberration in plague. The pain in the glands may cause the features to appear pain-drawn, or the intensity of the prostration may inducea woeful or haggard expression. When the pain has abated or before it becomes severe, the expression is usually placid or quite fatuous, the patient appearing quite apathetic or unconcerned as to his condition. When the patient is questioned as to his state he may return u seemingly intelligent answer; but on more careful inquiry it is usually found that the answers are quite haphazard and wholly untrue. Delirium may usher in the disease, especially in the pneumonic or fulminant varieties; but in moderately severe types of bubonic plague the delirium may not appear until after several days, when it is more apt to be a busy, rather than a furious, delirium. In severe cases the patient would seem as though possessed of suicidal tendencies, rushing to the window, out into the street, and otherwise behaving as if quite maniacal. Plague patients may be found walking in the street as if in a dream, or may take passage by boat or railway not knowing what they are doing. As a rule gentle remonstrance turns the patient from his parpose; but on the other hand, as in pneumonic plague, true mania appears, the patient struggling with his attendants, and attempting to do them bodily harm. When walking, the patient appears to stagger and reel as if intoxicated, and the loss of co-ordination may be so marked that he is quite unable, even in the early stages of the disease, to unbutton his clothing or raise food or drink to his mouth. Tremors, muscular twitchings, convulsions, picking at the bedclothes, etc., are ordinary features of the disease, and towards the end the patient sinks into a comatose condition. Early in the illness the patient may become deaf: and thickness of speech, due evidently to lingual paresis, is almost a diagnostic feature.

Sleeplessness is one of the most distressing symptoms in plague. Its continuance is indicative of a serious condition, and to procure sleep always becomes one of the chief aims of treatment.

The temperature in a typical case of bubonic plague of moderate virulence follows a fairly constant course. During the first $t$ wo days the temperature rises gradually until per- 
haps it attains a maximum of $104^{\circ}$ or $105^{\circ}$. During the third and fourth days it usually remains high, but towards the end of the fourth day it falls, and may approach or even fall below the normal. Towards the end of the fifth day or on the sixth day of the illness an increase in temperature is again to be expected, but the fever gradually subsides after the bubo has burst and discharged. It is, however, by no means rare to find that the thermometer registers $104^{\circ} \mathrm{F}$. or higher during the first few hours of the illness, and hyperpyrexia not infrequently obtains on the second and third days. When after the second rise and fall in temperature fever recurs, it generally signifies a septic infection, and is usually followed by a fatal result. Apyrexia is not common in true bubonic plague, wat in such opposite conditions as pestis ambulans and fulmivant plague apyrexia is the rule.

\section{II.-Pneumonic Plague.}

During the epidemic of plague in Bombay, Childe observed that concomitantly with the increase of mortality from bubonic plague deaths from pneumonia multiply pari passu. Investigations led to the discovery that in the sputum of these pneumonic cases the plague bacilli existed in swarms, and that the so-called septic pneumonia was indeed due to plague. Pneumonic plague is usually ushered in by a rigor, dyspn œe, cough, a high temperature, and marked prostration. The sputum is profuse, of a watery character at first ; it may be tinged with blood from the onset, but more usually blood does not appear until after twenty-four hours' duration of the illness. Pneumonic patches-lobular pneumonia-occur in either lung, and at any portion of the lungs, but are more usually met with in the lower lobe and towards the posterior aspect; moist sounds, especially at the base, and bronchial râles are to be heard, but all the signs and symptoms are peculiarly evanescent; and a patch of pneumonic tissue, dull to-day, clears op to-morrow, and another part of the lung becomes affected. The pulee is eoft and compressible from the first and cardiac distress is considerable. Delirium, frequently of a violent type, prevails, but before death coma supervenes, preceded, it may be, by a muttering delirium. The pneumonic variety of plague is a most rapidly fatal form of the disease, the patient usually dying on the third or fourth day.

\section{III.-Septicagmio Prague.}

With this type of plague are associated such terms as toxic, ulminant, and siderans, all indicative of the virulence of the attack and the fatal nature of the disease. The severity of the onset is such that the patient seems struck down as if by an active poison, and the prostration from the first is so extreme that the strength of the patient seems unable to resist the depressing influences at work. The glands may be felt to be enlarged, but there may be no bubo. So slight is the swelling of the glands that it is usually only during postmortem examination that their enlargement is to be madeout but so generally are the glands involved that every gland in every group in the body may be swollen. Hæmorrhages from the nose, bowel, or kidney are more frequently present in the septic variety of plague than in any other type of the disease. Apyrexia is a not uncommon feature of theailment, the depressing influences of the illness being apparently sopronounced that reaction would seem to be impossible. Delirium of $a$ busy or typhoid type, muscular twitchings, tremors. or picking at the bedclothes, prevail, followed by coma, which usually ends in death on the second or third day of the illness.

\section{Pathological anatomy.}

Bubonic Plague.

On the skin of a person dead of plague mas be fonnd petechiæ here and there; and over the bubo itself and on the limb on which the bubo develops, dusky patches, sometimes punctate but more often irregular in outline are met with, causing the skin to appear mottled. A rash resembling the eruption in typhus is very occasionally met with. The skin, more especially of the hands and feet, should be carefully examined for wounds, and the skin generally for evidence of bites, scratchings, abrasions, etc. Boils and so-called carbuncles are very occasionally found. The bubo, when sut into, shows a periglandular effusion with odema, usually widely spread around the group of glands. The effasion may be sero-sanguinolent, sero-purulent, or may consist of coagulated blood for the most part. The tissues are matted together so as to be indistinguishable from one another, and it is only when the glands are reached that a definite structure can be made out. All the glands of the group in which the bubo exists will be found swollen and congested to about the size of a hazel nut, but one of the number may be as big as a walnut or pigeon's egg. It is this gland, around which the periglandular effusioniexists, which causes the bun-shaped mass designated a bubo.

As a rule, every gland in the body, whether in the limbs, abdomen, or thorax, is found post mortem to be somewhat enlarged; and the name "polyadenitis" well describes the condition. In consistence the less swollen glands are firm, and in colour pink on section; but the large glands are soft or even diffluent to touch, and appear of a darker colour when cut into. In many bodies, when the inguinal group of glands is the seat of a bubo, a chain of inflamed and enlarged glands can be traced upon in the iliac region, and even to the lumbar region. The mesenteric or the post-peritoneal glands may be the only apparent seats of enlargement and of extravasation of blood.

On proceeding to open the body the viscera will be found generally to be congested, and the serous and mucous membranes to be the seat of petechiæ or hæmorrhages.

The lungs, although they may be cdematous, are not markedly affected in bubonic plague; a careful search may reveal the presence of minute hæmorrhages or localised congestions. The pleural fluid exceeds the normal in amount, and is frequently blood-stained. Parietal and visceral subpleural hæmorrbages or petechiæ are of common occurrence. The bronchial mucus will be found frothy, and a tinge of blood may colour it.

The Heart and Pericardium.-The pericardial fluid amounts to some two or three or more onnces, and is oceasionally bloodstained; petechiæ on the parietal and visceral layers of the pericardium are frequently seen. The right side of the heart appears dilated, and the heart muscle generally appears cloudy as if from fatty degeneration. In the cavæ and the large veins at the root of the neck subendothelial hæmorrhages may be expected to be found.

The Peritoneum and Abdominal Viscera.-The subperitoneal tissues of the abdominal wall and of the several viscera may be studded with petechiæ, or extensive hæmorrhages may occur into the omentum, mesentery, in the retroperitoneal regions, more especially in the neighbourhood of the kidney. The iliac, lumbar, and mesenteric glands will be found swollen and congested, and in some instances markedly so, with a great amount of periglandular effusion. The walls of the stomach and intestines are congested, and in the submucous tissues hæmorrhages are frequent. The solitary glands and Peyer's patches are always prominent, and in cases in which life has been prolonged for a week or more they may be ulcerated. The fæcal contents of the intestine may be bloodstained or clots of blood may intermingle with the fæces. The liver is congested, a little enlarged perhaps, and somewhat softened in consistence. The gall bladder is, as a rule, full of bile and its coats may be involved in a subhepatic hæmorrhage. The spleen is swollen to three or more times its natural bulk; hæmorrhages beneath the capsule may extend for some distance into the splenic tissue.

The kidneys are congested, enlarged, and the peri-renal fat may be occupied by extravasated blood which occasionally extends in all directions, but mostly downwards along the track of the ureter. The stellate veins of the kidney are prominent, the capsule peels off readily, and small hæmorrhages may be found between the capsule and the renal cortex. When cut into the cortical tissue seems swollen, the pyramids congested, and the whole organ the seat of clondy swelling. Blood may fill the renal pelvis and extend down into the ureter and bladder. The bladder may be full or empty, the urine normal or bloodstained, and petechiæ may or may not be present in the inner wall.

The Nervous System.-Meningeal congestion, œdema of the substance of the brain, and prominent vascular puncta seen on section sum up the changes in the nervous system met with in plague. The pia mater is occasionally the seat of ecchymosis.

The lungs, after death due

due to pneumonic plague, appear cdematous, engorged with venous blcod, and are the seat of 
basal congestion and of patchy pneumonic consolidation; the consolidated areas are usually localised, varying froan an area corresponding in size to a marble to that of an orange. Around the airless patches a margin of crepitant and deeplycoloured lung tissue is to be found. The pleural surfaces are usually dotted with petechiæ, and occasionally with fair-sized subpleural hæmorrhages. The linings throughout the respiratory tract are reddened, injected, and show here and there hæmorrhages in the submucous tissue; a frothy bloodtinged mucus is commonly found occupying the passages.

The changes in the other viscera of the body are similar to those met with in bubonic plague; but there are no buboes, nor are enlarged glands, as a rule, met with anywhere in the body.

Septicamic Plague.

The glands, in septicæmic plague, over the whole body are congested and swollen, in most instances to only a small extent, but in one group and frequently in one gland of the group adenitis has advanced considerably. There are no buboes, but a gland may be seen as big as a hazel nut here and there. When cut into the glands are pink in colour and of a firm rather tough conslstence, but, in some of the larger sized, localised areas of softening occur. The visceral engorgement and congestion with petechiæ and subendothelial and submucous hæmorrhages are features in septicæmic plague in common with all other varieties of the disease.

\section{NOTES ON THE INTRODUCTION OF A CASE OF PLAGUE INTO THE NEIGHBOURHOOD OF CARDIFF.}

By E. WALFORD, M.D., D.P.H.,

Medical Officer of Health for the Borough and Port of Cardiff.

THE danger of this country becoming infected by plague occurring on board vessels during a comparatively long voyage is one which cannot be ignored in view of the recent importation into the neigh bourhood of Cardiff of an undoubted and tolerably well-defined example of the bubonic variety of the disease. The main facts connected with this particular case heve been recorded, so that it will be unnecessary to add to any extent to the information already given. That the cases of illness which occurred amongst the firemen during the voyage of the South Garth from Rosario to King's Lynn were cases of plague is an assumption based almost entirely upon the light of subsequent events. If cases of pestis minor can be easily overlooked by medical practitioners, it is tolerably certain that they will not receive much attention at the hands of the ordinary master of a vessel, who does not as a rule exercise a very close medical supervision over his crew. The South Garth left Rosario about August 2oth, and calling at Buenos Aires shipped in place of an old hand, who deserted, a new one - an Austrian - who acted as third engineer. When the steamer arrived at King's Lynn in September this man, who was seriously ill, was sent ashore to a hospital, but the nature of his illness, although a matter of great interest, has not yet transpired. The other members of the crew taken ill during the voyage were firemen shipped at Barry or Cardiff on the outward voyage to South America. The point of interest in the etiology is the determination of the method by which the disease was conveyed from Rosario and the infected ports in the River Plate to South Shields during a voyage of about thirty-three days. Apart from personal infection in connection with these doubtful or suspicious cases, there is the possibility of the cargo having becume in some way infected. of some infected articles having been taken on board, and of the disease having been conveyed by means of rats. With respect to the cargo. it is to be remarked that this was discharged at King's Lynn between September i2th and 21 st.

The man attacked with plague (W. G., the donkeyman) was found on his arrival at his house in Llandaff on Sept. 26th to be very ill, and had presumably been ill for some days. On admission to the Borough Hospital of Cardiff on October and he had the appearance of a man in the second or third week of a severe attack of typhoid fever. The incubation would thus probably date from some time within the period of discharg. ing the cargo of maize, and the origin may have been due to the disturbance of this cargo. Rats were plentiful on board, and at varions times several dead ones were noticed; possibly some of these rodents may have introduced the infection into the maize, and others may have become infected from it. There is no evidence that the patient was bitten or had touched any rat, and the method of infection in this, as in many other cases, remains obscure.

The chief precautionary measures devolved of course upon the rural sanitary authority in whose district the case occurred, and these consisted in the immediate jsolation of the patient in the hospital of the adjoining urban eanitary district of Cardiff, in the medical examination of all persons who were in contact with the plague case, and the keeping under observation of "suspects" during the necessary period, and in disinfection or destruction of articles likely to be infected.

As regards the urban and port districts of Cardiff special precautionary measures have been adopted since the first introduction of the disease into Europe. Assistant medical officers and additional inspectors have been appointed to enable the authority to maintain an inspection of vessels from infected and suspected ports. Careful medical inspection of sailors' lodging houses is being carried out; inspection and cleansing of courts and dirty houses; circulars to medical practitioners relating to the notification of the disease. An infectious disease hospital has been provided with nearly 200 beds, and with separate buildings for the isolation of any such special cases, and furnished with a separate administrative department and staff. The destruction of rats on board vessels and in the neighbourhood of the docks has been carried out extensively during the past two months; about 2,000 of these animals have been caught and burned. The Port Sanitary Authority has, besides a hospital on the Flat Holm Island (about three miles from the shore), a very complete crematorium with mortuary and post-mortem room attached. The remains of the deceased, who died two days after admission into hospital, were on this occasion cremated in this apparatus, which was constructed by Messrs. Goddard and Massey, and, on the first occasion of its use, worked admirably, the entire remains being reduced to ashes in less than two hours.

The Port Sanitary Authority has compulsory powers under a local Act of Parliament for the cremation of persons dying from cholera, yellow fever and plague, but in this instance the full consent of the relatives was obtained.

As these remarks are only intended as an 'introduction! to the clinical and bacteriological notes which are of chief interest in this case, I have only to add that on this, as on many other occasions, the bacteriological laboratory, maintained jointly by the Glamorgan County Council and the Cardiff Corporation, was of extreme value, and the positive evidence of the presence of Kitasato's bacillus, given by Dr. Savage, our bacteriologist, at the earliest possible date, was completely confirmed by him by cultural and inoculation experiments, and by the subsequent investigation of $\mathrm{Dr}$. Klein.

\section{A CASE OF PLAGUE FROM A CLINICAL AND PATHOLOGICAL POINT OF VIEW.}

\author{
WILLIAM G. SAVAGE, and \\ B Sc., M.D.Lond., D.P.H., \\ Bacteriologist to the Cardiff and \\ County Public Health Labora-
} tory; Lecturer on Bacteriology, University College, Cardiff.

THE rarity of plague in this country, and the completeness with which we were enab'ed to investigate the following case is our excuse for giving the notes of it somewhat in detail. The vast majority of cases recorded and the bulk of work done in connection with this disease has been carried out abroad, and few cases are available for comparison between the disease as met with in tropical and in more temperate climates. This case agrees in the main with the classical descriptions derived from cases studied in the tropics.

\section{Clinical Report.}

$$
\text { History. }
$$

W. G., aged 38, donkeyman on board ss. South Garth, left 